JOURNAL OF PUBLIC HEALTH INOVATION,

VOL. 01 NO.02. JUNI 2021

DOI: $10.34305 /$ jphi.v1i2.269
Ciptaan disebarluaskan di bawah

Lisensi Creative CommonsAtribusi-

NonKomersial-BerbagiSerupa 4.0

Internasional.

\title{
HUBUNGAN ANTARA DUKUNGAN KELUARGA DENGAN KELENGKAPAN IMUNISASI DASAR PADA BALITA
}

\author{
A Asrina, Siti Nunung Nurjannah, Aen Siti Nuraini \\ STIKes Kuningan \\ asrina.andiamir@gmail.com
}

\begin{abstract}
Abstrak
Beberapa alasan anak tidak diimunisasi antara lain karena takut anaknya panas, keluarga tidak mengizinkan, tempat imunisasi jauh, kesibukan orang tua, seringnya anak sakit, dan tidak tahu tempat imunisasi. Keluarga mempunyai peranan sangat penting dalam upaya peningkatan kesehatan dan pengurangan resiko penyakit dalam masyarakat. Tujuan penelitian untuk mengetahui hubungan antara dukungan keluarga dengan kelengkapan pemberian imunisasi dasar pada balita. Jenis penelitian yang digunakan adalah analitik dengan rancangan cross sectional, jumlah populasi 317 responden, jumlah sampel 177 responden, teknik sampel simple random sampling. Instrumen penelitian menggunakan kuesioner, buku KIA dan laporan bulanan bidan desa. Analisis data menggunakan Chi Square. Hasil analisis univariat, sebagian besar status imunisasi dasar lengkap $(64,4 \%)$ dan keluarga responden sebagian besar mendukung imunisasi $(71,2 \%)$. Analisi Bivariat, diperoleh nilai $p$ value sebesar 0.032, sehingga $\mathrm{Ha}$ diterima. Artinya terdapat hubungan antara dukungan keluarga dengan kelengkapan imunisasi. Kesimpulan terdapat hubungan dukungan keluarga dengan kelengkapan pemberian imunisasi dasar pada balita. Saran bagi bidan diharapkan bidan dapat meningkatkan pelayanan dan dapat memberikan penyuluhan kepada ibu-ibu yang mempunyai balita sehingga dapat di imunisasikan dengan lengkap.
\end{abstract}

Kata kunci $\quad$ : Dukungan, Keluarga, Imunisasi

Pendahuluan

Angka Kematian Ibu (AKI) dan Angka Kematian Bayi (AKB) merupakan salah satu indikator utama derajat kesehatan suatu negara. AKI dan AKB juga mengindikasikan kemampuan dan kualitas 
JOURNAL OF PUBLIC HEALTH INOVATION,

VOL. 01 NO.02. JUNI 2021

DOI: $\underline{10.34305 / \text { jphi.v1i2.269 }}$

pelayanan kesehatan, kapasitas pelayanan kesehatan, kualitas pendidikan dan pengetahuan masyarakat, kualitas kesehatan lingkungan, sosial budaya serta hambatan dalam memperoleh akses terhadap pelayanan kesehatan (Kementerian Kesehatan RI, 2020).

Saat ini status kesehatan ibu dan anak di Indonesia masih jauh dari yang diharapkan, ditandai dengan masih tingginya AKI, dan AKB. Berdasarkan Survei Demografi dan Kesehatan Indonesia (SDKI) data $\mathrm{AKB}$ di Indonesia tercatat mengalami penurunan yaitu dari sebesar 35 per 1000 kelahiran hidup (2002) menjadi sebesar 34 per 1000 kelahiran hidup (2007), kemudian menjadi 32 per 1000 kelahiran hidup (2012). Terakhir tahun 2019 sebesar 24 per 1000 kelahiran hidup (Kesehatan Kemenkes RI, 2020).

Merujuk pada penyebab kematian bayi terbanyak disebabkan oleh masalah neonatal seperti BBLR, asfiksia, diare, pneumonia, serta beberapa penyakit infeksi lainnya, dimana penyakit infeksi tersebut dapat dicegah dengan imunisasi (Kementerian Kesehatan RI, 2014). Bayibayi yang baru lahir dan balita memiliki risiko tinggi terserang penyakit-penyakit menular yang mematikan, seperti difteri, tetanus, hepatitis B, campak, polio,
Ciptaan disebarluaskan di bawah Lisensi Creative CommonsAtribusiNonKomersial-BerbagiSerupa 4.0

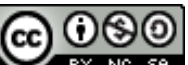

influenza, tifus, radang selaput otak, radang paru-paru dan masih banyak penyakit lainnya yang sewaktu-waktu muncul dan mematikan. Untuk itu, salah satu pencegahan yang terbaik dan sangat vital adalah dengan melakukan imunisasi (Ronald, 2011)

Imunisasi adalah pemberian kekebalan tubuh terhadap suatu penyakit dengan memasukan sesuatu ke dalam tubuh agar tahan terhadap suatu penyakit yang sedang mewabah atau berbahaya bagi seseorang. Tujuan dari pemberian imunisasi adalah untuk mengurangi angka penderita suatu penyakit yang sangat membahayakan kesehatan, bahkan bisa menyebabkan kematian pada penderitanya (Putra, 2012). Menurut Direktur Jenderal Pengendalian Penyakit dan Penyehatan Lingkungan Kementerian Kesehatan dr HM Subuh di Indonesia Imunisasi Dasar Lengkap (IDL) pada tahun 2015 mencapai $86,8 \%$, dan perlu ditingkatkan hingga mencapai target $93 \%$ di tahun 2019. Universal Child Immunization (UCI) desa yang kini mencapai $82,9 \%$ perlu ditingkatkan hingga mencapai 92\% di tahun 2019. Sedangkan di tingkat nasional pada akhir tahun 2016 target imunisasi dasar lengkap 91,5 \% dan UCI desa $86 \%$ (Kementerian Kesehatan Republik Indonesia, 2015). 
JOURNAL OF PUBLIC HEALTH INOVATION,

VOL. 01 NO.02. JUNI 2021

DOI: $10.34305 /$ jphi.v1i2.269

Data cakupan imunisasi di Provinsi Jawa Barat pada tahun 2012 jumlah cakupan imunisasi BCG sebanyak 94,1 \%, DPT 1 sebanyak 91,8\%, DPT 2 sebanyak 81,2\%, DPT 3 sebanyak 73,8\%, Polio 1 sebanyak $95,2 \%$, Polio 2 sebanyak $88,7 \%$, Polio 3 sebanyak 77,0\%, Hepatitis 0 sebanyak $89,2 \%$, Hepatitis 1 sebanyak 78,0\%, Hepatitis 2 sebanyak 69,5\%, Hepatitis 3 sebanyak $41,8 \%$, Campak sebanyak $81,1 \%$, dan Semua vaksinasi dasar tanpa hepatitis B sebanyak 65,6\% (Badan Kependudukan dan Keluarga Berencana Nasional, 2012). Sedangkan pada tahun 2013 adalah $\mathrm{Hb} 0$ adalah 98.2\%, BCG 106.2\%, DPT/Hb (3) 102.7\%, Polio $4102.1 \%$ dan Campak 101.5\% (Dinas Kesehatan Jawa Barat, 2014).

Data cakupan Imunisasi di Dinas Kesehatan Kabupaten Ciamis pada tahun 2012 jumlah cakupan imunisasi DPT+Hb1 sebanyak 97,4 \%, DPT3+HB3 sebanyak $100 \%$, Campak sebanyak 100\%, BCG sebanyak 94,1 \%, dan Polio Sebanyak 99, 53\%. Akan tetapi pada tahun 2013 cakupan Imunisasi Campak di Kabupaten Ciamis turun menjadi 92,8. Data cakupan imunisasi dasar lengkap di Wilayah kerja Puskesmas Kecamatan Rajadesa Kabupaten Ciamis tahun 2014 adalah sebanyak $73.2 \%$, sedangkan untuk data cakupan imunisasi di
Ciptaan disebarluaskan di bawah

Lisensi Creative CommonsAtribusi-

NonKomersial-BerbagiSerupa 4.0

Internasional.

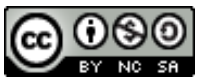

Desa Sukajaya Kecamatan Rajadesa Kabupaten Ciamis tahun 2014 adalah sebanyak $58.2 \%$ (Departemen Kesehatan RI, 2014).

Beberapa alasan anak tidak diimunisasi antara lain karena takut anaknya panas, keluarga tidak mengizinkan, tempat imunisasi jauh, kesibukan orang tua, seringnya anak sakit, dan tidak tahu tempat imunisasi(Departemen Kesehatan RI, 2014). Keluarga merupakan sumber bantuan yang terpenting bagi anggota keluarganya atau bagi individu yang dapat mempengaruhi gaya hidup atau mengubah gaya hidup anggotanya menjadi berorientasi pada kesehatan. Keluarga mempunyai peran penting dalam membantu anggota keluarganya untuk hidup yang lebih sehat. Keluarga mempunyai peranan sangat penting dalam upaya peningkatan kesehatan dan pengurangan resiko penyakit dalam masyarakat karena keluarga merupakan unit terkecil dalam masyarakat (Setyowati, 2008). Maka dari itu untuk meningkatkan kelengkapan pemberian imunisasi dasar pada balita di suatu wilayah diperlukan adanya dukungan dari keluarga.

Berdasarkan hasil studi pendahuluan yang penulis lakukan terhadap 10 orang ibu yang mempunyai dengan cara wawancara didapatkan data bahwa 5 dari 10 orang ibu 
JOURNAL OF PUBLIC HEALTH INOVATION,

VOL. 01 NO.02. JUNI 2021

DOI: $10.34305 /$ jphi.v1i2.269

yang mempunyai balita mengatakan bahwa anaknya tidak diberikan imunisasi dasar lengkap karena tidak mendapatkan dukungan dari keluarga, alasan keluarga tidak mendukung karena takut anaknya menjadi sakit.

\section{Metode}

\section{Hasil}

\section{Tabel 1. Distribusi Frekuensi}

\begin{tabular}{c|c|c|c|}
\hline Variabel & Kategori & Frekuensi & Persentase $(\%)$ \\
\hline \multirow{2}{*}{$\begin{array}{c}\text { Dukungan } \\
\text { Keluarga }\end{array}$} & Mendukung & 126 & $\mathbf{7 1 , 2}$ \\
& Tidak Mendukung & 51 & $\mathbf{2 8 , 8}$ \\
\hline \multirow{2}{*}{ Imunisasi } & Total & $\mathbf{1 7 7}$ & $\mathbf{1 0 0}$ \\
& Lengkap & 114 & 64,4 \\
& Tidak Lengkap & 63 & 35,6 \\
\hline
\end{tabular}

\section{Sumber : Data Primer}

Berdasarkan tabel 1 sebagian besar

keluarga responden mendukung imunisasi, yaitu sebanyak 126 responden (71,2\%).

Sedangkan yang tidak mendukung sebanyak 51 responden $(28,8 \%)$. Selain itu, sebagian besar responden memiliki balita dengan
Ciptaan disebarluaskan di bawah Lisensi Creative CommonsAtribusiNonKomersial-BerbagiSerupa 4.0 Internasional.

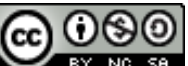

Jenis penelitian yang digunakan adalah analitik dengan rancangan cross sectional, jumlah populasi 317 responden, jumlah sampel 177 responden, teknik sampel simple random sampling. Instrumen penelitian menggunakan kuesioner, buku KIA dan laporan bulanan bidan desa. Analisis data menggunakan analisis statistik dengan uji Chi Square. status imunisasi dasar lengkap yaitu sebanyak 114 responden $(64,4 \%)$ dan responden yang memiliki balita dengan status imunisasi dasar tidak lengkap yaitu sebanyak 63 responden $(35,6 \%)$.

Tabel 2. Hubungan pengetahuan dan perilaku penatalaksanaan dismenorea

\begin{tabular}{|c|c|c|c|c|c|c|c|}
\hline \multirow{3}{*}{ Dukungan Keluarga } & \multicolumn{4}{|c|}{ Kelengkapan Imunisasi } & \multirow{2}{*}{\multicolumn{2}{|c|}{ Total }} & \multirow{3}{*}{ Nilai $p$} \\
\hline & \multicolumn{2}{|c|}{ Lengkap } & \multicolumn{2}{|c|}{ Tidak Lengkap } & & & \\
\hline & $\mathbf{f}$ & $\%$ & $\mathbf{f}$ & $\%$ & $\mathbf{N}$ & $\%$ & \\
\hline Mendukung & 95 & 83,3 & 31 & 49,2 & 126 & 100 & 0,032 \\
\hline Tidak Mendukung & 19 & 16,7 & 32 & 50,8 & 51 & 100 & \\
\hline
\end{tabular}

Sumber : Data Primer 
JOURNAL OF PUBLIC HEALTH INOVATION,

VOL. 01 NO.02. JUNI 2021

DOI: $10.34305 /$ jphi.v1i2.269

Berdasarkan tabel diatas, dari 126 balita yang mendapatkan dukungan keluarga sebanyak 95 responden $(83,3 \%)$ mendapatkan imunisasi lengkap dan sisanya sebanyak 31 responden $(49,2 \%)$ tidak mendapatkan imunisasi lengkap. Dari 51 balita yang tidak mendapatkan dukungan keluarga sebanyak 19 responden $(16,7 \%)$ mendapatkan imunisasi lengkap dan sisanya sebanyak 32 responden tidak mendapatkan imunisasi lengkap.

Berdasarkan uji statistik chi square dengan menggunakan SPSS dengan derajat kepercayaan $95 \%$ dan nilai $\alpha=0.05$ diperoleh nilai $\mathrm{P}$ value sebesar 0.032 . Karena $\mathrm{P}$ value $<\alpha$, maka keputusannya adalah Ha diterima, artinya terdapat hubungan antara dukungan keluarga dengan kelengkapan imunisasi.

\section{Pembahasan}

Berdasarkan penelitian didapatkan bahwa dari 177 responden mendapatkan dukungan keluarga sebanyak 126 responden (71,2\%), sedangkan yang tidak mendukung sebanyak 51 responden $(28,8 \%)$. Berdasarkan wawancara lanjutan dengan responden ternyata yang menyebabkan sebagian besar responden mendapatkan dukungan dari keluarga karena mendapatkan informasi tentang imunisasi, mendapatkan
Ciptaan disebarluaskan di bawah Lisensi Creative CommonsAtribusiNonKomersial-BerbagiSerupa 4.0 bantuan berupa materi maupun non materi dan beberapa responden mengatakan bahwa di dalam keluarganya sudah terbiasa memberikan imunisasi kepada anaknya.

Hal ini sesuai dengan teori yang dikemukakan (Suparyanto, 2012) dukungan keluarga didefinisikan informasi verbal, sasaran, bantuan yang nyata atau tingkah laku yang diberikan oleh orang-orang yang akrab dengan subjek di dalam lingkungan sosialnya atau yang berupa kehadiran dan hal yang dapat memberikan keuntungan emosional atau pengaruh pada tingkah laku penerimaannya.

Hasil penelitian yang dilakukan oleh (Ismet, 2013) tentang Analisis Faktor-faktor yang Berhubungan dengan Imunisasi Dasar Lengkap Pada Balita di Desa Botubarani Kecamatan Kabila Bone Kabupaten Bone Bolango menunjukan bahwa sebagian besar responden $(68,3 \%)$ mendukung terhadap pemberian imunisasi dan $(43 \%)$ tidak mendukung terhadap pemberian imunisasi.

Penelitian ini juga menunjukkan sebagian besar responden memiliki balita dengan status imunisasi dasar lengkap yaitu sebanyak 114 responden $(64,4 \%)$ dan responden yang memiliki balita dengan status imunisasi dasar tidak lengkap yaitu sebanyak 63 responden (35,6\%). Berdasarkan wawancara lanjutan dengan 
JOURNAL OF PUBLIC HEALTH INOVATION,

VOL. 01 NO.02. JUNI 2021

DOI: $\underline{10.34305 / \text { jphi.v1i2.269 }}$

responden ternyata tidak diberikan imunisasi dasar lengkap karena dari hasil pengamatan peneliti didapatkan bahwa sebagian responden takut efek samping dari pemberian imunisasi tersebut, takut anaknya menjadi rewel dan kurangnya penyuluhan tentang manfaat dan efek samping dari pemberian imunisasi.

Dalam penelitian ini dikatakan lengkap jika semua imunisasi telah diberikan dan dikatakan tidak lengkap jika salah satu belum diberikan. Menurut teori yang dikemukakan oleh (Putra, 2012), imunisasi terhadap suatu penyakit hanya akan memberikan kekebalan atau resistansi pada penyakit itu saja. Sehingga untuk terhindar dari penyakit lain, diperlukan imunisasi lainnya. Maka dari itu, pada bayi baru lahir, ada beberapa jenis imunisasi dasar yang wajib diberikan. Sehingga apabila imunisasi dasar tidak diberikan lengkap maka bayi/balita tersebut lebih beresiko terkena penyakit yang dapat dicegah oleh imunisasi.

Ibu yang mendapatkan dukungan keluarga berupa informasi, anjuran, dan pujian tentang imunisasi cenderung memiliki status imunisasi yang lengkap dibandingkan dengan yang memiliki status imunisasi tidak lengkap.

Hasil penelitian lain yang dilakukan oleh (Ningsih,Puspita \& Anggraeni 2013)
Ciptaan disebarluaskan di bawah

Lisensi Creative CommonsAtribusi-

NonKomersial-BerbagiSerupa 4.0

Internasional.

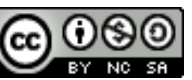

tentang Hubungan Peran Keluarga Dengan Kelengkapan Imunisasi Dasar Lengkap Pada Bayi Usia 10-12 Bulan Di Desa Batursari Rw 3, 4, 5 Dan 32 Kecamatan Mranggen Kabupaten Demak Tahun 2013 yang menyatakan bahwa ada hubungan yang bermakna antara peran keluarga dengan kelengkapan imunisasi dasar lengkap pada bayi usia 10-12 bulan di desa batursari RW 3, 4, 5 dan 32 Kecamatan Mranggen Kabupaten Demak dengan nilai $\mathrm{p}$ value $=$ $0,204(<0,05)$.

Hal ini sesuai dengan teori yang dikemukakan menurut (Suparyanto, 2012), dukungan keluarga didefinisikan informasi verbal, sasaran, bantuan yang nyata atau tingkah laku yang diberikan oleh orangorang yang akrab dengan subjek di dalam lingkungan sosialnya atau yang berupa kehadiran dan hal yang dapat memberikan keuntungan emosional atau pengaruh pada tingkah laku penerimaannya. Dalam hal ini orang yang merasa memperoleh dukungan sosial, secara emosional merasa lega diperhatikan, mendapat saran atau kesan yang menyenangkan pada dirinya. Dukungan keluarga sebagai adanya kenyamanan, perhatian, penghargaan, atau menolong orang dengan sikap menerima kondisinya, dukungan keluarga tersebut diperoleh dari individu maupun kelompok. 
JOURNAL OF PUBLIC HEALTH INOVATION,

VOL. 01 NO.02. JUNI 2021

DOI: $10.34305 /$ jphi.v1i2.269
Ciptaan disebarluaskan di bawah

Lisensi Creative CommonsAtribusi-

NonKomersial-BerbagiSerupa 4.0

Internasional.

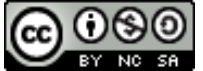

Dukungan keluarga dapat keputusan ibu untuk mengimunisasi memperkuat perilaku ibu dan dapat anaknya (Rahmatika, 2015).

menghambat perilaku ibu. Dukungan keluarga yang memperkuat perilaku ibu antara lain adalah mendukung untuk mengimunisasikan anaknya agar mempunyai kekebalan dan terhindar dari penyakit (terutama penyakit difteri, pertussis, dan tetanus) mengingatkan jadwal imunisasi bayinya, mengingatkan bahwa keadaan panas dari bayi adalah reaksi imunisasi dan suatu keadaan yang tidak berbahaya, bukan kontra indikasi untuk imunisasi berikutnya. Sedangkan dukungan keluarga yang memperlemah perilaku ibu untuk mengimunisasikan bayinya adalah sikap keluarga yang tidak mendukung ibu karena adanya efek samping dari imunisasi setelah bayi mendapat imunisasi. Seperti bayi menjadi panas dan atau ada benjolan di tempat suntikan, kemerahan di tempat suntikan, sehingga bayi tidak diijinkan untuk imunisasi berikutnya.

$$
\text { Melakukan penyuluhan dan }
$$
pendekatan persuasif pada keluarga tentang pentingnya imunisasi pada anak bisa dilakukan oleh petugas kesehatan bekerja sama dengan kader kesehatan. Hal ini diharapkan dapat meningkatkan dukungan keluarga terhadap pentingnya imunisasi sehingga mempengaruhi pengambilan

\section{Kesimpulan}

Terdapat hubungan dukungan keluarga dengan kelengkapan pemberian imunisasi dasar. Sebagian besar responden mendapatkan dukungan keluarga dan memiliki balita dengan imunisasi dasar yang lengkap.

\section{Daftar Pustaka}

Badan Kependudukan dan Keluarga Berencana Nasional. (2012). Persentase cakupan imunisasi.

Departemen Kesehatan RI. (2014). Lindungi Ibu Dan Bayi Dengan Imunisasi.

Dinas Kesehatan Jawa Barat. (2014). Cakupan Imunisasi2013.

Ismet, F. (2013). Analisis Faktor-faktor yang Berhubungan dengan imunisasi Dasar Lengkap Pada Balita di Desa Botubarani Kecamatan Kabila Bone Kabupaten Bone Bolango.

Kementerian Kesehatan Republik Indonesia. (2015). Kesehatan Dalam Kerangka Sustainable Development Goals (SDGs).

Kementerian Kesehatan RI. (2014). Jadilah Kartini Indonesia Yang Tidak Mati Muda Pencanangan Kampanye Peduli Kesehatan Ibu.

Kementerian Kesehatan RI. (2020). Profil Kesehatan Indonesia Tahun 2019. https://doi.org/10.5005/jp/books/11257 
JOURNAL OF PUBLIC HEALTH INOVATION,

VOL. 01 NO.02. JUNI 2021

DOI: $\underline{10.34305 / \text { jphi.v1i2.269 }}$
Ciptaan disebarluaskan di bawah Lisensi Creative CommonsAtribusiNonKomersial-BerbagiSerupa 4.0 Internasional.

Kesehatan Kemenkes RI. (2020). Data dan Informasi Profil Kesehatan Indonesia 2019. Kementerian Kesehatan RI.

Ningsih, P. \& A. (2013). Hubungan Peran Keluarga Dengan Kelengkapan Imunisasi Dasar Lengkap Pada Bayi Usia 10-12 Bulan Di Desa Batursari $R w$ 3, 4, 5 Dan 32 Kecamatan Mranggen Kabupaten Demak.

Putra, S. R. (2012). Asuhan Neonatus Bayi Dan Balita Untuk Keperawatan Dan Kebidanan. Jakarta: D-Medika.

Rahmatika, D. (2015). Faktor-faktor yang berhubungan dengan status imunisasi dasar pada bayi Di kelurahan mergosono kecamatan kedungkandang kota malang.

Ronald. (2011). Pedoman Perawatan Balita. CV Nuansa Aulia.

Setyowati, A. (2008). Asuhan Keperawatan Keluarga. In Mitra Cendikia Press.

Suparyanto. (2012). Konsep dukungan keluarga. 